that a reluctance to refer patients for unpleasant investigations was a factor, as was the patients' age, particularly if they were over 75 or under 40 .

We found that the mean delay from the onset of symptoms to surgical treatment was 19 weeks for left sided carcinomas and 29 weeks for right sided carcinomas. This is an improvement on the 38 and 31 weeks, respectively, of $1979 .{ }^{4}$ This may be due to increased recognition of the symptoms of colorectal cancer: 202 patients (70\%) with left sided tumours and $77(87 \%)$ with right sided tumours were referred urgently with the correct diagnosis. The apparent improved accuracy in diagnosing right sided malignancies was at the expense of a longer period of symptoms, possibly representing a lack of awareness by the patients of the importance of their general ill health. General practitioners detected $56 \%$ of palpable tumours, including $70 \%$ of the low rectal carcinomas. Twenty seven (12\%) patients with easily palpable tumours were referred for treatment of haemorrhoids without prior rectal examination; they were seen routinely and treatment was delayed.

Although we found an improvement in referrals by general practitioners over the past decade, an accurate rectal examination in each patient would have improved matters further. Patients with symptoms thought sufficient to warrant referral to a surgeon should not be denied a prior rectal examination.

1 Chapuis PH, Dent OF, Fisher R, et al. A multivariate analysis of clinical and pathological variables in prognosis after resection of large bowel cancer. Brf Surg 1985;72:698-702.

2 Umpleby HC, Bristol JB, Rainey JB, Williamson RCN. Survival of 727 patients with single carcinomas of the large bowel. Dis Colon Rectum 1984;27:803-10. 3 Keddie N, Hargreaves A. Symptoms of carcinoma of the colon and rectum. Lancet 1968;ii:749-50.

Holliday HW, Hardcastle JD. Delay in diagnosis and treatment of symptomatic colorectal cancer. Lancet 1979;i:309-11.

5 Vellacott KD, Roe AM, Mortensen NJMcC. An evaluation of a direct access flexible fibreoptic sigmoidoscopy service. Ann R Coll Surg Engl 1987;69: 149-52.

(Accepted 3 April 1990)

\section{Methaemoglobinaemia in children treated with prilocaine- lignocaine cream}

\section{M Frayling, G M Addison, K Chattergee, G Meakin}

Royal Manchester Children's Hospital, Manchester M27 1HA I M Frayling, $\mathrm{MB}$, registrar in chemical pathology G M Addison, PHD, consultant chemical pathologist

K Chattergee, FCANAES, registrar in anaesthesia G Meakin, FCANAES, lecturer

Correspondence to: Dr Meakin.

BrMed f 1990;301:153-4 in paediatric anaesthesia (eutectic mixture of local anaesthetics), Astra Pharmaceuticals) in reducing the pain of venepuncture and other minor skin procedures in children is well established. It is particularly useful in patients who require repeated skin puncture. ${ }^{1}$ The preparation contains prilocaine $25 \mathrm{~g} / \mathrm{l}$ and lignocaine $25 \mathrm{~g} / \mathrm{l}$ in an oily base. Prilocaine is associated with methaemoglobinaemia, two of its metabolites, 4-hydroxy-2-methylaniline and 2 -methylaniline (o-toluidine), having been implicated in this condition.

The most alarming report of methaemoglobinaemia after the use of prilocaine-lignocaine cream concerned a 3 month old infant who became cyanosed after $5 \mathrm{~g}$ of the cream was applied. ${ }^{2}$ His methaemoglobin concen-
The efficacy of prilocaine-lignocaine cream (Emla

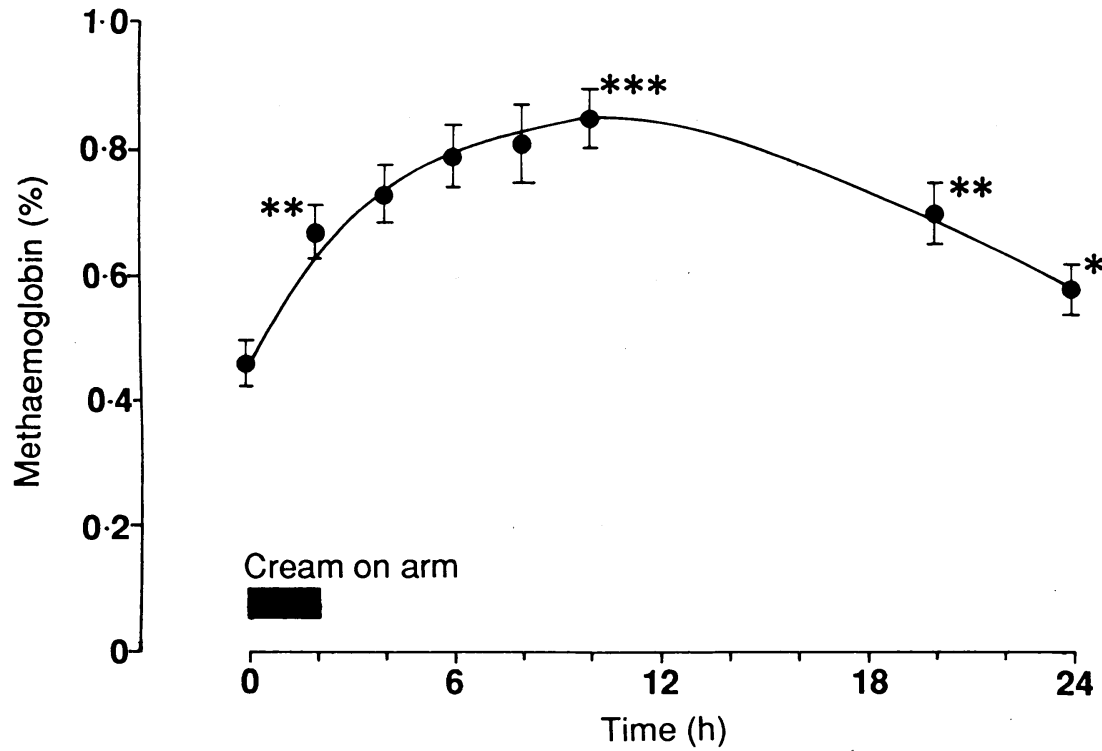

Relation between mean methaemoglobin concentration and time after application of prilocaine-lignocaine cream to arm.

${ }^{\star} p<0.05, \star \star p<0.01, \star \star \star p<0.001$ Compared with values in control children tration was $28 \%$, although this may have been partly due to concomitant treatment with a sulphonamide drug. More recently Engberg et al showed a slight increase in methaemoglobin concentration in infants treated with $2 \mathrm{~g}$ of the cream. ${ }^{34}$ The maximum concentration found was about $2 \%$, but some increase was still apparent 12 hours after the cream was applied.

We measured methaemoglobin concentrations in children up to 24 hours after a single application of $5 \mathrm{~g}$ of prilocaine-lignocaine cream.

\section{Patients, methods, and results}

We studied 48 healthy children aged 1-6, comprising 30 who presented for elective surgery and a control group of 18 who required routine haematological investigations. All the children undergoing surgery had prilocaine-lignocaine cream applied under occlusive dressings on their arms two hours before surgery. The cream was removed by a dry cotton swab immediately before intravenous injection of thiopentone. During anaesthesia an intravenous cannula was inserted into the long saphenous vein at the ankle for sampling venous blood and for fluid treatment. Blood was taken from 12 children two, four, six, eight, and 10 hours after the cream was applied; from six children 20 hours after the cream was applied; and from 12 children 24 hours after the cream was applied. A sample of blood was taken from each of the 18 control children, who did not receive the cream; the samples were treated and tested in the same way as those from the children who received the cream.

Each $2 \mathrm{ml}$ blood sample was collected into a specimen tube containing the anticoagulant dipotassium EDTA and taken to the laboratory for analysis within one hour. The haemoglobin and methaemoglobin concentrations were measured with an IL282 CO-Oximeter (Instrumentation Laboratory UK). Differences in the concentrations between the children who received the cream and the control group were determined with Student's two tailed $t$ test, and the null hypothesis was rejected when $\mathrm{p}<0.05$.

The figure shows the results. The mean methaemoglobin concentration in the control group was 0.46 (SE 0.04$) \%$. The methaemoglobin concentration in the children who received the cream increased to a maximum of $0.85(0.05) \% 10$ hours after application $(\mathrm{p}<0.001)$. This had fallen to $0.70(0.05) \%$ by 20 hours and to $0.58(0.04) \%$ by 24 hours; both these concentrations were still significantly greater than the control value $(\mathrm{p}<0.01$ and $\mathrm{p}<0.05$ respectively) 


\section{Comment}

We found a small but significant increase in methaemoglobin concentration in 1-6 year old children after routine administration of $5 \mathrm{~g}$ of prilocainelignocaine cream before surgery. Although the peak methaemoglobin concentration observed was well within safe limits, the finding of an increased concentration 24 hours after administration suggests that cumulative effects may occur in children receiving the cream daily. Some of these may be at special risk owing to pre-existing anaemia, coadministration of sulphonamide antibiotics, or reduced renal excretion of metabolites of prilocaine. The minimum effective dose should be used in all children requiring daily applications of prilocaine-lignocaine cream.

\footnotetext{
Clarke S, Radford M. Topical anaesthesia for venepuncture. Arch Dis Child 1986;61:1132-5

2 Jakobson B, Nilsson A. Methaemoglobinaemia associated with a prilocainelidocaine cream and trimethoprim-sulphamethoxazole. A case report. Acta Anaesthesiol Scand 1985;29:453-5.

3 Engberg G, Danielson S, Henneberg S, Nilsson A. Plasma concentrations of prilocaine and lidocaine and methaemoglobin formation in infants after epicutaneous application of a $5 \%$ lidocaine-prilocaine cream (EMLA). Acto Anaesthesiol Scand 1987;31:624-8.

4 Nilsson A, Engberg G, Henneberg S, Danielson K, DeVerdier C-H. Inverse relationship between age-dependent erythrocyte activity of methaemoglobin reductase and prilocaine-induced methaemoglobinaemia during infancy. Br f Anaesth 1990;64:72-6.

(Accepted 25 April 1990)
}

\title{
Uptake of immunisation against hepatitis $B$ among surgeons in Wessex Regional Health Authority
}

\author{
John R Williams, Alistair D S Flowerdew
}

\begin{abstract}
Department of Surgery, Royal United Hospital, Bath BA1 3NG

John R Williams, BM, surgical senior house officer Alistair D S Flowerdew, MS, surgical senior registrar
\end{abstract}

Correspondence to: $\mathrm{Dr}$ Williams.

BrMed f 1990;301:154
Infection with hepatitis B virus is a serious hazard for all health workers. Surgeons are particularly at risk,' with potentially devastating consequences to their wellbeing and a major threat to their livelihood if they become carriers. Immunisation is cheap (about 135 ) and readily available and should reduce if not abolish the number of carriers. We assessed the uptake of and policy on immunisation against hepatitis B among surgeons working in Wessex region.

\section{Subjects, methods, and results}

We sent questionnaires to all general surgeons, regardless of their grade, and to all 15 occupational health departments in Wessex region. The surgeons were asked about their immunisation state; whether immunisation had been encouraged; whether their present employer had asked about their immunisation state; and whether seroconversion had been tested for after immunisation. The questionnaire sent to the occupational health departments contained questions on their policies on immunisation and testing for seroconversion.

We received a reply from $76(78 \%)$ of the 97 surgeons, of whom 66 had been immunised, nine had not been immunised, and one had contracted hepatitis B. The overall uptake rate showed little difference between the grades of surgeon (table). Sixty two of the

Number (percentage) of surgeons who had been immunised against hepatitis $B$ according to grade

\begin{tabular}{lcrrc}
\hline & $\begin{array}{c}\text { Questionnaires } \\
\text { sent out }\end{array}$ & $\begin{array}{c}\text { Replies } \\
\text { received }\end{array}$ & $\begin{array}{c}\text { Surgeons } \\
\text { immunised }\end{array}$ & $\begin{array}{c}\text { Surgeons not } \\
\text { immunised }\end{array}$ \\
\hline Consultant & 45 & $38(84)$ & $31(82)$ & $6(16)$ \\
Senior registrar & 7 & $3(43)$ & $3(100)$ & \\
$\begin{array}{l}\text { Registrar and clinical } \\
\text { assistant }\end{array}$ & 30 & $25(83)$ & $22(88)$ & $3(12)$ \\
Senior house officer & 15 & $10(66)$ & $10(100)$ & \\
\hline Total & 97 & $76(78)$ & $66(87)$ & $9(12)$ \\
\hline
\end{tabular}

surgeons said that they had sought immunisation themselves. Only 34 claimed to have received any encouragement to be immunised (by occupational health departments (20), senior colleagues (eight), or other sources (six)). Only 17 of the surgeons had been approached about their immunisation state by their present employer. Thirty one of the 66 surgeons who had been immunised had been tested to see whether seroconversion had occurred.

All 12 of the 15 occupational health departments that replied had a policy of immunising all medical staff against hepatitis $B$. Ten monitored the immunisation state of all their medical staff, and all checked for seroconversion three to six months after immunisation.

\section{Comment}

Health service staff are at increased risk of infection with hepatitis B virus: as a group their risk has been estimated to be four times that of the general population. ${ }^{1}$ High risk groups such as surgeons have a 10 -fold increased risk. In one study immunisation led to a $92 \%$ decrease in the number of infections. ${ }^{2}$

Recent reports have suggested that the uptake of immunisation among health service workers is low, ${ }^{3}$ being only $39 \%$ in one study. ${ }^{4}$ Doctors are not exempt from this poor uptake as Kinnersley reported that only $287(48 \%)$ of 598 general practitioners had been immunised against hepatitis B. ${ }^{5}$ Our study showed an encouraging rate of immunisation in surgeons compared with other groups of doctors. ${ }^{35}$ Despite good evidence of an increased risk of infection a high proportion of surgeons in this study had not been immunised. This must represent a failure in preventive medicine as immunisation against hepatitis $B$ has been available for nearly a decade. Although all the occupational health departments had a policy of immunising all medical staff, only a quarter of the surgeons had been encouraged to be immunised by the department. Five departments spontaneously commented that doctors were the most difficult to contact and immunise. In our hospital a quarter of new junior doctors failed to attend the occupational health department despite repeated reminders. Of those who did attend, two thirds had been or were being immunised.

Clearly, there is a failure by all surgeons to protect themselves and to insist that junior staff are protected. Consultants and employers need to ensure that all junior staff are immunised, even to the extent of making it compulsory. Occupational health departments must ensure that their messages are heeded.

We thank Dr Derek C Heap for help and advice.

1 Dienstag JL, Ryan DM. Occupational exposure to hepatitis B virus in hospital personnel: infection or immunisation? Am f E pidemiol 1982;115:26-39. 2 Szmuness W, Stevens CE, Harley EJ, et al. Hepatitis B vaccine. Demonstration of efficacy in a controlled clinical trial in a high-risk population in the United States. N Engl f Med 1980;303:833-41.

3 Baddick MR, Tar-Ching A. Immunisation against hepatitis B among NHS staf in West Midlands Regional Health Authority. Br Med f 1989;299:607.

Scapa E, Karpuch J, Waron M, Eshchar J. Attitude of hospital personne towards hepatitis B vaccination. Am $\mathcal{J}$ Gastroenterol 1989;84:400-2.

5 Kinnersley P. Attitudes of general practitioners towards their vaccination against hepatitis B. BrMed f 1990;300:238.

(Accepted 23 April 1990) 